\title{
Assessment of Serum Level of IL-27 in Pregnancies Complicated by Preeclampsia
}

M.E.Fouda ${ }^{1}$, M.A.Mohamed ${ }^{2}$, O.S.El-Shimi ${ }^{1}$, R.A.Khashaba ${ }^{1}$ and O.M.Abou Zeid ${ }^{1}$

${ }^{1}$ Clinical \& Chemical Pathology Dept., Faculty of Medicine, Benha Univ., Benha, Egypt

${ }^{2}$ Gynecology \& Obstetrics, Dept., Faculty of Medicine, Benha Univ., Benha, Egypt

\section{Abstract}

E-Mail:Ola@gmail.com

Toxemia (PE) is characterized as new-beginning hypertension creating following 20 weeks' incubation with at least one of the accompanying: proteinuria, maternal organ brokenness (counting renal, hepatic, hematological, neurological complica-tions), as well as fetal development restriction.Aim and destinations: The point of this examination was to think about serum levels of IL-27 between preeclamptic ladies with obviously solid pregnant and non-pregnant women.Methods: One hundred and twenty females went to Gynecology and Obstetrics office and outpatient facility, Benha University Hospitals were partitioned into three gatherings; understanding gathering: included 40 pregnant ladies with PE, typical pregnant gathering: included 40 females with ordinary pregnancy and non-pregnant gathering: included 40 evidently sound non-pregnant female.Results: Serum IL-27 was essentially higher in toxemia cases more than the sound pregnant and non-pregnant controls $(\mathrm{P}<0.001)$. End: Serum IL-27 might be helpful in determination of pregnant ladies compilicated by toxemia.

Keywords: Preeclampsia (PE), Interleukin-27 (IL-27).

\section{Introduction}

Toxemia (PE) is characterized as hypertension creating following 20 weeks' development with at least one of the accompanying: proteinuria, maternal organ brokenness (counting renal, hepatic, hematological, neurological complicattions), and additionally fetal development limitation [1].

PE is generally analyzed by the presence of hypertension

$(\geq 140 / 90 \mathrm{mmHg}$ ), joined by proteinuria $(\geq 300$ $\mathrm{mg} / 24 \mathrm{~h}$ or $\geq 1+$ on a dipstick) or maternal organ brokenness [2].

Interleukin-27 (IL-27) is a heterodimeric cytokine that contains Epstein-Barr infection prompted quality 3 (EBI3) and IL-27p28, which signals through a receptor made out of gp130 (used by numerous cytokines, including IL-6) and IL-27R $\alpha$ (likewise known asWSX1 or TCCR) [3].

The prevailing cell wellsprings of IL-27 are viewed as myeloid cell populaces, which incorporate macrophages, provocative monocytes, microglia, and dendritic cells (DCs), despite the fact that plasma cells, endothelial cells, and epithelial cells express IL-27 [4].

Toxemia was discovered to be related with a higher middle maternal serum convergence of IP-10 than typical pregnancy. Furthermore, IL-27 was found to prompt the statement of IP-10 and IL- 6 in trophoblast cells by means of the enactment of a few flagging pathways [5].

\section{Study subjects}

This investigation was led on 120 females of coordinated age took care of Gynecology and Obstetrics division and outpatient facility, Benha University Hospitals, separated into three gatherings, tolerant gathering: included 40 pregnant ladies with toxemia (PE), ordinary pregnant gathering: included 40 females with typical pregnancy and non-pregnant gathering: included 40 clearly sound non-pregnant female with coordinated age.
Incorporation measures: All patients were remembered for the examination if toxemia was analyzed following 20 weeks of incubation, as per the accompanying models: Blood pressure higher than $140 / 90 \mathrm{mmHg}$ at 2 separate events, 4 hours separated. Or then again Blood pressure higher than or equivalent to $160 / 110 \mathrm{mmHg}$, Along with critical proteinuria $\geq 300$ $\mathrm{mg} / \mathrm{L}$ in a 24 -hour pee assortment or a dipstick perusing of $\geq 1+$ on a voided arbitrary pee test without urinary plot contamination [6].

\section{Prohibition models}

Any subject was barred from the examination, in the event that she had: eclampsia, HELLP condition, gestational diabetes, clinical chorioamnionitis, harm, urinary parcel disease (UTI), any irresistible issues or some other reason for proteinuria.

This examination was acted in agreement to the moral rules of the 2004 Declaration of Helsinki. The examination convention was endorsed by the nearby morals advisory group on research including human subjects of Faculty of Medicine, Benha University. Educated assents were gotten from all members preceding their enlistment in the examination.

\section{Techniques}

All selected subjects were assessed by: Full history: including: Present history: name, age, weight, long stretches of incubation, primigravida or multigravida .Obstetric history: of unsuccessful labor and toxemia. Family background: of pregnancy actuated hypertension and toxemia. Research facility Investigations: During the antenatal consideration; included: Liver capacity tests (ALT, AST and egg whites), total blood picture, proteinuria and serum interleukin 27 (IL-27) level.

Factual examination:

Information were taken care of to the $\mathrm{PC}$ and examined utilizing IBM SPSS programming bundle form 20.0 (Armonk, NY: IBM Corp). Subjective 
information were portrayed utilizing number and percent. Quantitative information were portrayed utilizing mean \pm standard deviation $(S \mathrm{D})$ or middle and interquartile range (IQR). Chi-square test: changed for downright factors, to analyze between various gatherings. Understudy t-test: for regularly circulated quantitative factors, to look at between two contemplated gatherings. F-test (ANOVA): for typically disseminated quantitative factors, to think about between multiple gatherings, and Post Hoc test (Tukey) (LSD) for pairwise correlations.

\section{Results}

A case-control study conducted on 120 women attending to Gynecology and Obstetrics department and outpatient clinic, Benha University Hospitals, between July and November 2019. 40 preecalmpsia (group I), 40 normal pregnant (group II) and 40 normal non-pregnant control (group III).

Table (1) Comparison of blood pressure between the studied groups. Both systolic and diastolic blood pressure were significantly higher in preeclampsia cases compared to the apparently normal pregnant and non-pregnant females ( $\mathrm{P}<0.001$ each).

Table (2) Distribution of the studied preeclampsia cases according to severity. Twenty two $(55 \%)$ of preeclampsia cases had mild, 8 patients $(20 \%)$ had moderate and $10(25 \%)$ of patients had severe disease.

Table (3) Comparison of the fetal data between the studied pregnant subjects. The mean fetal age at delivery in preeclampsia patients was $35.58 \pm 2.99$ weeks which was significantly lower than in the normal pregnant controls $38.55 \pm 1.22$ weeks $(\mathrm{P}<0.001)$. The birth weight of babies born to preeclampsia mother was significantly lower than in normal pregnant females $(\mathrm{P}$ $<0.001)$. The mean baby birth weight in preeclampsia patients was $2115.0 \pm 680.61$ grams while in apparently normal pregnant controls was $3412.50 \pm 491.95$ grams.

Regarding fetal outcome; in preeclampsia cases $45 \%$ of fetus were born preterm, $12.5 \%$ were IUFD and $42.5 \%$ were born at full term which was statistically significant compared to the apparently normal pregnant females whose babies were all born at full term (P $<0.001)$.

Table (1) Comparison of blood pressure between the studied groups.

\begin{tabular}{lccccc}
\hline $\begin{array}{l}\text { Blood pressure } \\
(\mathbf{m m H g})\end{array}$ & $\begin{array}{c}\text { Preeclampsia } \\
(\mathbf{n}=\mathbf{4 0})\end{array}$ & $\begin{array}{c}\text { Normal pregnancy } \\
(\mathbf{n}=\mathbf{4 0})\end{array}$ & $\begin{array}{c}\text { Non-pregnant } \\
(\mathbf{n}=\mathbf{4 0})\end{array}$ & $\mathbf{F}$ & $\mathbf{P}$ \\
\hline $\begin{array}{l}\text { Systolic } \\
\text { Mean } \pm \text { SD }\end{array}$ & $159.25 \pm 9.17$ & $105.75 \pm 12.33$ & $108.50 \pm 10.27$ & 318.993 & $<0.001$ \\
$\begin{array}{l}\text { Diastolic } \\
\text { Mean } \pm \text { SD }\end{array}$ & $103.25 \pm 6.16$ & $70.0 \pm 8.77$ & $70.50 \pm 6.77$ & 271.102 & $<0.001$ \\
\hline
\end{tabular}

F: ANOVA test.

Table (2) Distribution of the studied preeclampsia cases according to severity $(n=40)$.

\begin{tabular}{lcc}
\hline Severity & N. & \% \\
\hline Mild & 22 & 55.0 \\
Moderate & 8 & 20.0 \\
Severe & 10 & 25.0 \\
\hline
\end{tabular}

Table (3) Comparison of the fetal data between the studied pregnant subjects.

\begin{tabular}{|c|c|c|c|c|c|c|}
\hline & \multicolumn{2}{|c|}{$\begin{array}{c}\text { Preeclampsia } \\
(n=40)\end{array}$} & \multicolumn{2}{|c|}{$\begin{array}{c}\text { Normal pregnancy } \\
(\mathrm{n}=\mathbf{4 0})\end{array}$} & Test & $\mathbf{P}$ \\
\hline \multicolumn{7}{|l|}{ Fetal age at delivery (ws) } \\
\hline Mean \pm SD & \multicolumn{2}{|c|}{$35.58 \pm 2.99$} & \multirow{2}{*}{\multicolumn{2}{|c|}{$38.55 \pm 1.22$}} & $t=5.820$ & $<0.001$ \\
\hline \multicolumn{5}{|l|}{ Birth weight (grams) } & & \\
\hline Mean \pm SD & \multicolumn{2}{|c|}{$2115.0 \pm 680.61$} & \multicolumn{2}{|c|}{$3412.50 \pm 491.95$} & $t=9.772$ & $<0.001$ \\
\hline Outcome baby & N. & $\%$ & N. & $\%$ & & \\
\hline Preterm & 18 & 45.0 & 0 & 0.0 & & \\
\hline IUFD & 5 & 12.5 & 0 & 0.0 & $\chi^{2}=35.859$ & $<0.001$ \\
\hline Full term & 17 & 42.5 & 40 & 100.0 & & \\
\hline
\end{tabular}

t: Student t-test, $\chi^{2}$ : Chi square test.

\section{Discussion}

The point of this examination was to think about serum levels of IL-27 in preeclamptic ladies, obviously sound pregnant and non-pregnant females and to assess its connection with illness seriousness and neonatal results.

To understand the focused on point, this examination was led on 40 patients with toxemia, 40 
clearly sound pregnant and 40 solid non-pregnant ladies as a benchmark group. All patients and controls were exposed to full history taking and clinical assessment. Research facility examinations remembered protein for pee, liver capacity tests [serum egg whites, AST and ALT], complete blood check and serum IL-27 level.

In current examination, both systolic and diastolic pulse were fundamentally higher in toxemia cases contrasted with the clearly ordinary pregnant and nonpregnant females $(\mathrm{P}<0.001$ each). These outcomes were in concurrence with [7]. (2018) who announced essentially higher systolic circulatory strain, diastolic pulse and proteinuria in preeclamptic ladies contrasted and solid gatherings $(\mathrm{P}<0.0001)$ [7]. demonstrated that ladies with beginning stage toxemia had higher mean blood vessel pulse levels at 20 weeks of incubation, contrasted with the normotensive gathering. They found that ladies with late-beginning toxemia had higher mean blood vessel pulse levels at 37 weeks of growth, than the normotensive gatherings [8]. Additionally, [9] affirmed that the mean changes of systolic and diastolic pulse in PE ladies expanded by 4.66 and $2.55 \mathrm{mmHg}$, separately, contrasted with the non-PE gathering, after change for age, and BMI at benchmark [9].

Our investigation included $22(55 \%)$ of toxemia cases with gentle, 8 patients $(20 \%)$ with moderate and $10(25 \%)$ of patients with serious sickness. While,[10]. showed that between 245 moms, the seriousness of toxemia was 14 ladies $(5.7 \%)$ with gentle toxemia and $222(90.6 \%)$ ladies with extreme toxemia [10].

In our examination the mean fetal age at conveyance in toxemia patients was $35.58 \pm 2.99$ weeks which was fundamentally lower than in the clearly typical pregnant controls $38.55 \pm 1.22$ weeks $(\mathrm{P}<0.001)$. This was in accordance with [11]. who indicated that ladies with extreme toxemia conveyed altogether before 33-37 weeks' incubation (mean gestational age $35.9 \pm 3.2$ weeks) than the normotensive ladies [11].

We likewise saw that the birth weight of children destined to toxemia moms was altogether lower than in the clearly typical pregnant females $(\mathrm{P}<0.001)$. The mean child birth weight in toxemia patients was $2115.0 \pm 680.61$ grams while in evidently ordinary pregnant controls was $3412.50 \pm 491.95$ grams. This concurred with [7]. (2018), who indicated that birth weight in preeclamptic ladies was essentially lower than solid pregnant ladies $(\mathrm{P}<0.0001)$ [7].

With respect to result; in toxemia cases $45 \%$ of hatchling were conceived preterm, $12.5 \%$ were IUFD and $42.5 \%$ were conceived at full term which was measurably huge contrasted with the evidently typical pregnant females whose children were totally conceived at full term ( $\mathrm{P}<0.001)$. This was in accordance with [12]. who indicated that kids brought into the world after a pregnancy muddled by toxemia have a normal of 5\% lower birth weight when contrasted with youngsters brought into the world after a simple pregnancy and an expanded fetal passing rate;
5.2 per 1000 fetal demise in ladies with toxemia versus 3.6 per 1000 in ladies with straightforward pregnancies (12). These outcomes were likewise in concurrence with [13]. who uncovered that the mean birth weight diminished to $2339.3 \pm 729.4$ grams; and gestational age at conveyance diminished to $36.4 \pm 2.2$ weeks, and both these patterns were measurably critical $(\mathrm{P}<0.001)$. Likewise embryos had a high danger frequency of preterm conveyance, little for gestational age upon entering the world/low birth weight at term [13].

\section{Coclusion}

Our study revealed that serum IL-27 was significantly higher in preeclampsia cases rather than healthy pregnant and non-pregnant controls. So finally we can conclude that IL-27 has a good diagnostic value in diagnosis of preeclampsia.

\section{Reference}

[1] K.Duhig, B.Vandermolen, A. Shennan. Recent advances in the diagnosis and management of preeclampsia. Women's Health Academic Centre, King's College London, Vol.7, PP.242, 2018.

[2] M.L Pan, L.R Chen, H.M Tsao Risk of gestational hypertension-preeclampsia in women with preceding endometriosis: A nationwide populationbased study. PLOS ONE, Vol.12(7), PP.e0181261,2017.

[3] S.Pflanz, L.Hibbert, J.Mattson, WSX-1 and glycoprotein 130 constitute a signal-transducing receptor for IL-27. J immunol. (Baltimore, Md : 1950), Vol.172(4), PP.2225-2231,2004.

[4] A.O Hall, J .S Silver, C.A Hunter. The immunobiology of IL-27. Adv Immunol. A, Vol.115, PP.1-44,2012.

[5] N.Yin, H.Zhang, X.Luo, IL-27 activates human trophoblasts to express IP-10 and IL-6: implications in the immune pathophysiology of preeclampsia. Mediat Inflamm, Vol.50, PP.361-369,2014.

[6] J.M Roberts, P.A August, G.Bakris, Hypertension in pregnancy. Report of the American College of Obstetricians and Gynecologists'Task Force on Hypertension in Pregnancy. Obstet Gynecol, Vol.122 (5), PP.1122-1131,2013.

[7] D.Jahantigh, M.Mousavi, F.Forghani, Association between maternal circulating IL-27 levels and preeclampsia. Cytokine, Vol.102, PP.163$167,2018$.

[8] J.Mayrink, R.T Souza, F.E Feitosa, Mean arterial blood pressure: potential predictive tool for preeclampsia in a cohort of healthy nulliparous pregnant women. BMC Pregnancy Childb, Vol.19(1),2019.

[9] M. Amiri, F.Ramezani Tehrani, M.Rahmati, Changes over-time in blood pressure of women with preeclampsia compared to those with normotensive pregnancies: A 15 year populationbased cohort study. Pregnancy Hypertens, Vol.17, PP.94-99,2019.

[10] V.Leidner, F.Markfeld-Erol, M.Wuttke, Maternal 
blood pressure levels prepartum correlate with neonatal birth weight in preeclampsia. J Perinat Med,2019.

[11] J.Mateus, R.B.Newman, C.Zhang, Fetal Growth Patterns in Pregnancy-Associated Hypertensive Disorders: NICHD Fetal Growth Studies. Am J Obstet Gynecol, 2019.

[12] A,Bokslag, M,van Weissenbruch,B,W,Mol, de Groot CJM. Preeclampsia; short and long-term consequences for mother and neonate. Early Hum Dev, Vol.102, PP.47-50, 2016.

[13] A.Vasudeva, A.A.Abraham,A. A.Kamath prospective observational study of early fetal growth velocity and its association with birth weight, gestational age at delivery, preeclampsia, and perinatal mortality. Eur J Radiol, Vol.82(8), PP.1313-1317,2013. 